\title{
Clinical Reasoning: A young woman with symmetric weakness and behavioral disturbance
}

Jon Rosenberg, MD, Whitley Aamodt, MD, Samuel Takvorian, MD, and Michael Mullen, MD

Neurolog ${ }^{\circledR}$ 2018;90:e1442-e1447. doi:10.1212/WNL.0000000000005335

\section{Section 1}

A 19-year-old woman presented with altered mental status and progressive quadriparesis. One week prior to admission, she experienced headaches and behavior changes, including social withdrawal and a fixation on electronics. The day prior to admission, she developed weakness in both arms, and was unable to lift them above her head, followed shortly thereafter by proximal leg weakness and difficulty climbing stairs. The next day, she was intermittently unresponsive and unable to stand without assistance. Her medical history was notable for supraventricular tachycardia and depression. She was on an estrogen-containing oral contraceptive and fluvoxamine, which had been started for depression 6 weeks prior to admission. She had also recently completed a course of amoxicillin for bronchitis. She had no pertinent family history. Her social history was significant for IV heroin use approximately 2 months prior to admission. Her initial examination was notable for disorientation to time and place and impaired concentration and short term memory, with intact language and cranial nerves. There was $2 / 5$ strength in both her arms and legs, with preserved sensation to light touch and vibration, and $2+$ reflexes, although a Babinski sign was present bilaterally.

\section{Questions for consideration}

1. Where would you localize this lesion?

2. What is your differential based on this localization?

\author{
Correspondence \\ Dr. Rosenberg \\ jon.rosenberg@uphs. \\ upenn.edu
}

\section{MORE ONLINE}

\section{ค Podcast}

Dr. Dan Ackerman interviews Dr. Jon Rosenberg about his Clinical Reasoning paper describing a young patient with symmetric weakness.

NPub.org/5113qo

\section{GO TO SECTION 2}




\section{Section 2}

The presence of cognitive impairment, quadriparesis, and bilateral Babinski signs suggests a CNS process affecting both cerebral hemispheres with or without spinal cord or corticospinal tract involvement. These symptoms are consistent with encephalitis or encephalomyelitis. The differential diagnosis for an acute to subacute encephalitis/encephalomyelitis in a young adult includes autoimmune conditions, such as acute demyelinating encephalomyelitis, multiple sclerosis, neuromyelitis optica, Bickerstaff encephalitis, and sarcoidosis, along with infections, such as West Nile, enterovirus D68/A71, herpes simplex virus (HSV), varicella-zoster virus (VZV), and Lyme disease. Given the patient's social history, toxic metabolic insults, such as drug intoxication, vitamin $\mathrm{B}_{12}$ deficiency, or heroin-associated leukoencephalopathy, should be considered. A venous sinus thrombosis can also be considered given she uses an estrogen-containing oral contraceptive. Other etiologies include CNS vasculitis (primary CNS angiitis or vasculitis secondary to systemic disease) and paraneoplastic syndromes, such as anti-NMDA receptor encephalitis and anti-Hu-associated encephalomyelitis, are also possible, though less likely given the rapid onset and progression of the symptoms.

\section{Question for consideration}

1. What initial testing would you consider?

Routine laboratory studies revealed a leukocytosis $(12,300$ cells $/ \mu \mathrm{L})$, peripheral eosinophilia $(2,706$ cells $/ \mu \mathrm{L})$, and elevated troponins $(8 \mathrm{ng} / \mathrm{mL})$. The patient had a normal sedimentation rate, lipid panel, and $\mathrm{HbAlc}$; negative drug screen, pregnancy test, and HIV screening; and normal rapid plasma reagin, blood cultures, and antineutrophilic cytoplasmic, antinuclear, anti-SSA/SSB, and hepatitis B and C antibodies. A lumbar puncture revealed no cells, normal protein and glucose levels, and negative HSV and VZV serologies. MRI brain without contrast showed bilateral acute watershed infarcts in the internal and external border zones (figure).

\section{Questions for consideration}

1. What is your differential for ischemic stroke in a young adult?

2. How does the infarct distribution change your differential?

Figure MRI brain
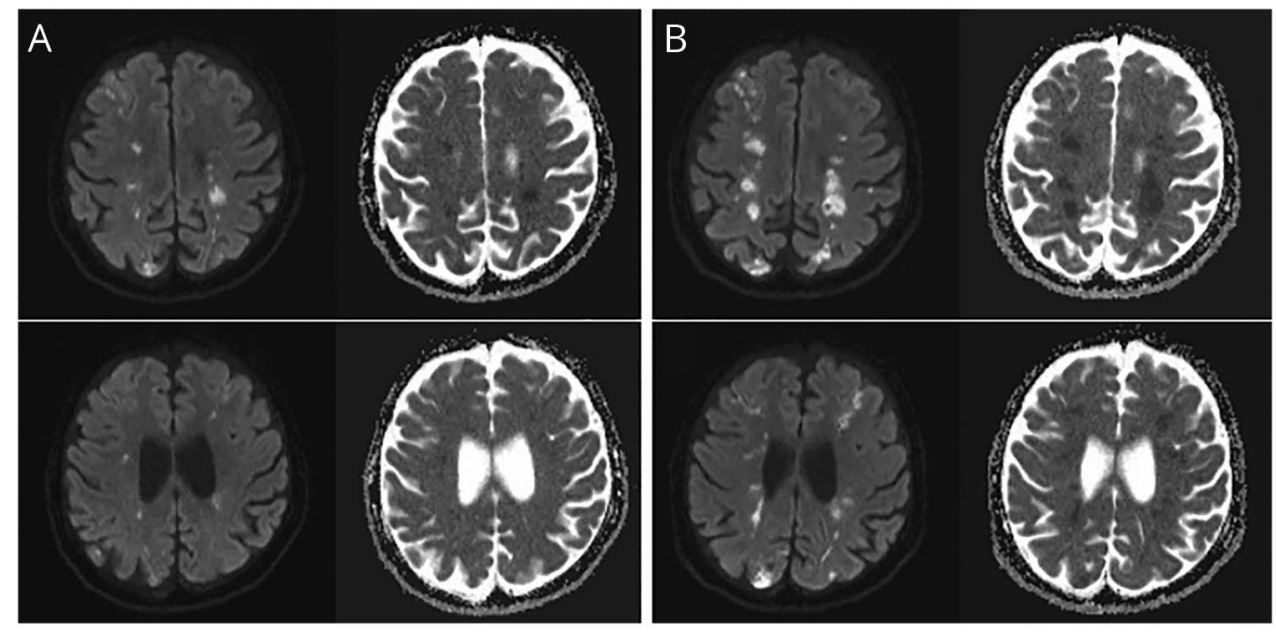

Axial diffusion-weighted sequences with apparent diffusion coefficient correlate.Initial brain MRI (A) shows acute bilateral watershed infarcts. Subsequent brain MRI (B) 3 days later shows new acute infarcts in a similar bilateral watershed distribution. 


\section{Section 3}

Most ischemic strokes in young adults are cryptogenic, though the differential is broad. ${ }^{1}$ In addition to cardioembolism, arterial dissection, large vessel atherosclerosis, and small vessel disease, less common conditions, such as inherited (factor V Leiden and prothrombin gene mutations) and acquired thrombophilias (antiphospholipid antibody syndrome, hypercoagulability of malignancy, nephrotic syndrome), sickle cell disease, nonatherosclerotic arteriopathies (e.g., vasculitis, Moyamoya), and drugs should be considered in this population. ${ }^{1}$ Reversible cerebral vasoconstriction syndrome (RCVS) can also present with ischemic stroke, though hemorrhage is more common.

The MRI showed bilateral infarcts involving both the internal and external border zones, sparing the basal ganglia, thalamus, and brainstem. Internal border zone infarcts typically result from cerebral hypoperfusion secondary to rapid blood pressure changes, while cortical border zone infarcts are suggestive of embolism. ${ }^{2}$ Given the patient's' history of cardiac arrhythmia and IV drug use, cerebral hypoperfusion, cardioembolism, or septic emboli from endocarditis were considered. CNS vasculitis typically causes multifocal asymmetric strokes of different ages involving the cortex and deep brain tissue in addition to the border zone areas. ${ }^{3}$ Moreover, the MRI findings were not consistent with venous sinus thrombosis.

\section{Question for consideration}

1. What further investigations would you consider?

A repeat MRI of the brain with contrast 48 hours later showed new acute infarcts in a similar watershed distribution (figure, B). MRI of the cervical spine, CT angiogram of the head, neck, and chest, and transthoracic and transesophageal echocardiograms were unrevealing.

\section{Question for consideration}

1. Do these results change your differential? 


\section{Section 4}

The normal echocardiography, vessel imaging, spinal fluid, rheumatology laboratories, blood cultures, and absence of fever argue against cardioembolism, endocarditis, arterial dissection, RCVS, vasculitis, and infection. There was no history of hypotension, hypoxia, arrhythmia, or cardiac arrest. Moreover, the patient's mean arterial pressure was normal throughout her hospital stay, making cerebral hypoperfusion unlikely. The infarct distribution, in combination with encephalopathy, peripheral eosinophilia, and cardiac injury, suggest stroke secondary to hypereosinophilic syndrome.

\section{Discussion}

The hypereosinophilic syndromes (HES) are a rare group of disorders characterized by hypereosinophilia (greater than 1,500 eosinophils $/ \mu \mathrm{L}$ ) and the presence of eosinophil-mediated organ injury or tissue infiltration. Patients most commonly present with dermatologic, cardiac, pulmonary, neurologic, or gastrointestinal symptoms. ${ }^{4}$ Hypereosinophilia can be driven by primary (clonal expansion) or secondary (reactive) etiologies, such as drugs, parasitic infections, autoimmune diseases, or malignancy. The definition of HES has evolved over time, prompting multiple classification schemes. ${ }^{4}$ We refer to HES in its broadest conception: hypereosinophilia with eosinophilmediated organ damage, regardless of the underlying cause. This classification system acknowledges that hypereosinophilia of any etiology can cause potentially life-threatening complications that may necessitate immediate eosinophil-lowering therapy.
The principal neurologic manifestations of HES are stroke, encephalopathy, and neuropathy. ${ }^{5}$ Stroke in HES is characterized by a distinct pattern of both internal and external border zone infarcts. ${ }^{5,6}$ The mechanism of stroke in HES is unknown. The cortical border zone distribution of infarcts, as well as the detection of endomyocardial fibrosis, ventricular thrombus formation, and microemboli on cardiac imaging and transcranial Doppler ultrasounds in some patients, together support cardioembolism as a causative mechanism. ${ }^{5}$ Importantly, echocardiography may be nor$\mathrm{mal}$ in the acute necrotic stage of eosinophilic myocarditis, and so cannot be used to exclude this diagnosis. Cardiac MRI or biopsy is often needed to detect early endomyocardial fibrosis.

Hypereosinophilia, similar to plasma cell dyscrasias, may impair cerebral blood flow through a hyperviscosity-like syndrome. ${ }^{6}$ Furthermore, eosinophil degranulation results in the release of cationic and vasoactive proteins, which in addition to cardiac injury may cause endothelial damage and local hypercoagulability in the brain. ${ }^{7}$ Thus, HES may alter cerebral blood flow by causing local microthrombi formation or decreased clearance of microemboli. ${ }^{5,7}$ This idea is supported by perfusion imaging in patients with stroke and HES, which shows decreased capillary blood flow in areas of infarction that subsequently improves after treatment. ${ }^{7} \mathrm{Al}$ though the mechanism of encephalopathy in HES is unknown, it is possible that it is a manifestation of hyperviscosity and eosinophil-mediated toxicity to the CNS.

\section{Question for consideration}

1. What further testing is recommended?

GO TO SECTION 5 


\section{Section 5}

We consulted hematology, who recommended testing for both primary and secondary causes of hypereosinophilia. Chart review indicated that the patient had a normal eosinophil count 3 months prior to admission. Peripheral blood smear did not show evidence of dysplastic eosinophils. Peripheral flow cytometry did not reveal clonal lymphoid or myeloid cell populations. Molecular and cytogenetic testing for myeloid-associated neoplasms, including rearrangements in PDGFR A/B, FGFR1, BCR-ABL, JAK-2, and T-cell receptor, were unremarkable. CT scan of the chest, abdomen, and pelvis did not show evidence of occult malignancy. Stool ova-parasites, Strongyloides, Schistosoma, Trichinella, and Toxocara serologies were negative.

\section{Questions for consideration}

1. Do these findings change your diagnosis?

2. How would you treat this patient?

GO TO SECTION 6 


\section{Section 6}

There was no evidence of a neoplastic/clonal eosinophil disorder, such as eosinophilic leukemia or myeloproliferative hypereosinophilic syndrome, or that of an underlying infection or systemic disease. Given the unrevealing workup and normal eosinophil count prior to several new medication exposures, this condition was likely drug-induced HES secondary to heroin, fluvoxamine, or amoxicillin, all of which may be associated with drug-induced hypereosinophilia.,

Corticosteroids are the mainstay of HES treatment and should be initiated urgently if life-threatening complications are present. In HES secondary to parasitic infections, steroids should be coadministered with antihelminthic therapy, especially in the setting of Strongyloides infection to prevent potentially fatal dissemination. Prednisone $1 \mathrm{mg} / \mathrm{kg}$ daily or $60 \mathrm{mg}$ daily for $1-2$ weeks, followed by a $1-2$ months taper, is recommended. ${ }^{10}$ In PDGFR-associated myeloproliferative neoplasms, imatinib is the preferred therapy. ${ }^{10}$ In HES refractory to steroids, treatment with cladribine, cyclosporine, vincristine, or alemtuzumab can be considered. ${ }^{10}$

We administered IV methylprednisolone $1,000 \mathrm{mg}$ for 3 days then prednisone $60 \mathrm{mg}$ daily for 5 days and a subsequent 1-month taper. Our patient's eosinophilia resolved within 48 hours, and she began to lift her limbs antigravity. After 1 month, her mental status returned to baseline and she was walking unassisted.

Clinicians should be cognizant of hypereosinophilia in young patients who present with border zone cerebral infarctions, as rapid treatment with corticosteroids is indicated.

\section{Author contributions}

Jon Rosenberg: conception and drafting of the original manuscript along with critical revisions. Whitley Aamodt: drafting of the manuscript, critical revisions to the intellectual content, and figure creation. Samuel Takvorian: drafting of the manuscript and critical revisions to the intellectual content. Michael Mullen: editing and critical revisions to the intellectual content.

\section{Study funding}

No targeted funding reported.

\section{Disclosure}

The authors report no disclosures relevant to the manuscript. Go to Neurology.org/N for full disclosures.

\section{References}

1. Yesilot Barlas N, Putaala J, Waje-Andreassen U, et al. Etiology of first ever ischemic stroke in European young adults: the 15 cities young stroke study. Eur J Neurol 2013; 20:1431-1439.

2. Yong SW, Bang OY, Lee PH, Li WY. Internal and cortical border-zone infarction: clinical diffusion-weighted imaging features. Stroke 2006;37:841-846.

3. Gomes LJ. The role of imaging in the diagnosis of central nervous system vasculitis. Curr Allergy Asthma Rep 2010;10:163-170.

4. Simon HU, Rothenberg ME, Bochner BS, et al. Refining the hypereosinophilic syndrome. J Allergy Clin Immunol 2010;126:45-49.

5. Lago A, Parkhutik V, Tembl JI, et al. Embolism and impaired washout: a possible explanation for border zone strokes in hypereosinophilic syndrome. J Neurol Sci 2013;325:162-164.

6. MicMillan HJ, Johntson Doja A. Watershed infarction due to hypereosinophilia. Neurology 2008;70:80-82.

7. Tong LS, Wan JP, Cai X, Lou M. Global hypoperfusion: a new explanation of border zone strokes in hypereosinophilia. CNS Neurosci Ther 2014;20:794-796.

8. Nutman TB. Evaluation and differential diagnosis of marked persistent eosinophilia. Immunol Allergy Clin North Am 2007;27:529-549.

9. Bolz J, Meves S, Kara K, et al. Multiple cerebral infarctions in a young patient with heroin-induced hypereosinophilic syndrome. J Neurol Sci 2015;356:193-195.

10. Tefferi A, Gotlib J, Pardanani A. Hypereosnophilic syndrome and clonal eosinophilia: point of care diagnostic algorithm and treatment update. Mayo Clin Proc 2010;85: $58-164$. 


\section{Neurology}

\section{Clinical Reasoning: A young woman with symmetric weakness and behavioral disturbance}

Jon Rosenberg, Whitley Aamodt, Samuel Takvorian, et al.

Neurology 2018;90; 1442 -e 1447

DOI 10.1212/WNL.0000000000005335

\section{This information is current as of April 16, 2018}

\section{Updated Information \&} Services

References

Subspecialty Collections

\section{Permissions \& Licensing}

Reprints including high resolution figures, can be found at: http://n.neurology.org/content/90/16/e1442.full

This article cites 10 articles, 2 of which you can access for free at: http://n.neurology.org/content/90/16/e1442.full\#ref-list-1

This article, along with others on similar topics, appears in the following collection(s):

Autonomic diseases

http://n.neurology.org/cgi/collection/autonomic_diseases

Embolism

http://n.neurology.org/cgi/collection/embolism

Encephalitis

http://n.neurology.org/cgi/collection/encephalitis

Infarction

http://n.neurology.org/cgi/collection/infarction

Stroke in young adults

http://n.neurology.org/cgi/collection/stroke_in_young_adults

Information about reproducing this article in parts (figures,tables) or in its entirety can be found online at:

http://www.neurology.org/about/about_the_journal\#permissions

Information about ordering reprints can be found online: http://n.neurology.org/subscribers/advertise

Neurology ${ }^{\circledR}$ is the official journal of the American Academy of Neurology. Published continuously since 1951, it is now a weekly with 48 issues per year. Copyright () 2018 American Academy of Neurology. All rights reserved. Print ISSN: 0028-3878. Online ISSN: 1526-632X.

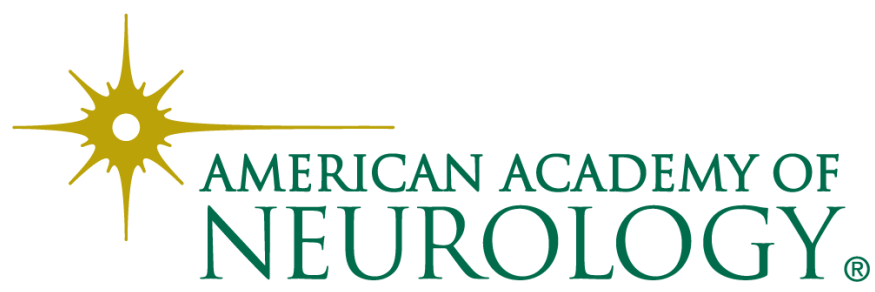

